\title{
Prediction of diffusion coefficients of chlorophenols in water by computer simulation
}

\author{
Luís F.G. Martins ${ }^{\mathrm{a}, *}$, M. Cristina B. Parreira ${ }^{\mathrm{a}}$, João P. Prates Ramalho ${ }^{\mathrm{a}}$, Pedro Morgado ${ }^{\mathrm{b}}$, \\ Eduardo J.M. Filipe ${ }^{b}$ \\ ${ }^{a}$ Centro de Química de Évora, Escola de Ciências e Tecnologia, Universidade de Évora, Rua Romão Ramalho, 59, 7000-671 Évora, Portugal \\ ${ }^{\mathrm{b}}$ Centro de Química Estrutural, Instituto Superior Técnico, Universidade de Lisboa, Av. Rovisco Pais, 1049-001 Lisboa, Portugal
}

\section{A R T I C L E I N F O}

\section{Article history:}

Received 29 December 2014

Received in revised form 4 March 2015

Accepted 11 March 2015

Available online 14 March 2015

Keywords:

Diffusion coefficients

Chlorophenols

Molecular dynamics

\begin{abstract}
A B S T R A C T
Intra-diffusion coefficients of seven chlorophenols (2-chlorophenol, 3-chlorophenol, 4-chlorophenol, 2,4-dichlorophenol, 2,6-dichlorophenol, 2,4,6-dichlorophenol and pentachlorophenol) in water were determined by computer simulation (molecular dynamics) for dilute solutions at three different temperatures and the corresponding mutual diffusion coefficients estimated. The mutual diffusion coefficients of 2-chlorophenol in water agree with the available experimental results from the literature for all the temperatures studied. From the dependence of the diffusion coefficients on temperature, diffusion activation energies were estimated for all the solutes in water. Analyzing the radial distribution functions and spatial distribution functions of water around chlorophenols sites enable a discussion about intermolecular interactions (dominated by hydrogen bonding) between solute and solvent and its importance on the relative magnitude of diffusion coefficients. Finally the mutual diffusion coefficients obtained by simulation were correlated by the well-known Wilke-Chang equation.
\end{abstract}

(c) 2015 Elsevier B.V. All rights reserved.

\section{Introduction}

Chlorophenols are hazardous and persistent pollutants that are present in surface and ground waters, and one of them (pentachlorophenol) is considered a priority substance by the recent European Directive 2013/39/UE [1]. They have been used worldwide as broad spectrum biocides in domestic, agricultural and industrial contexts [2]. Chlorophenols also found applications in extraction of sulfur and nitrogen compounds from coal [3], as wood preservatives, antiseptics (especially, 4-chlorophenol) [4] and as intermediate substances for the synthesis of many products such as highly chlorinated phenols (from mono and dichlorophenols), herbicides (in particular, phenoxyacetic acids), disinfectants, dyes, pharmaceuticals [5] and phenolic resins [6].

These substances (mainly mono and dichlorophenols) are also formed accidentally as by-products of drinking water disinfection [7], wood pulp and paper bleaching, incineration of solid residues [8] and as products of degradation of numerous pesticides [9], such as chlorobenzenes and chlorinated cyclohexanes. They can also be found in wastewaters of coal conversion and petroleum refining industries [10].

\footnotetext{
* Corresponding author. Tel.: +351 266745343; fax: +351 266744971

E-mail address: lfgm@uevora.pt (L.F.G. Martins).
}

In the environment, chlorophenols are found essentially in water but can also be detected in soils, sediments and biota [11]. The hydrophobicity of these compounds increases with the number of chlorine atoms in the molecule, with the consequent increasing tendency of the heavier ones to accumulate through the food chain.

Chlorophenols typically cause unpleasant taste and odor on drinking water, are harmful by ingestion and absorption by skin, causing cell necrosis and are suspected to have carcinogenic properties to the human body, essentially based on epidemiologic studies [12]. Because of the risks to the human health, the use of chlorophenols has been restricted in many countries [11]. However, since they are still in use in some other countries and due to their persistent character, chlorophenols still constitute a matter of environmental concern.

The removal of chlorophenols from water and wastewater has been done using a significant number of processes [13], such as liquid-liquid extraction [7], membrane extraction [14], pervaporation, solid-liquid adsorption [15,4,3,16,17], chemical processes (e.g., advanced oxidation process) [18] and biochemical methods based on microorganisms and enzymes [13].

The design of effective removal processes, dispersion and transport models of chlorophenols in water implies the knowledge of some key properties, such as the molecular mobility of in aqueous solutions, expressed by their diffusion coefficients. 
Despite their obvious importance, the diffusion coefficients of these compounds in water are scarce in literature and in many cases have to be estimated.

Niesner and Heintz [19] measured the mutual diffusion coefficients of a series of aromatic compounds in water, including 2-chlorophenol. More frequent is the measurement of diffusion coefficients of chlorophenols in polymeric membranes, such as polyether-polyamide block copolymers [20], HDPE geomembranes [21] or polyethylene films [22]. Given the difficulty in obtaining reliable experimental data for these systems due to their toxicity, low solubility, etc., computer simulations are a convenient tool to provide systematic estimations of the diffusion coefficients for the whole chemical family of chlorophenols in water.

Computer simulations involving chlorophenols are almost inexistent in the literature apart from the work of Plazinski et al. who modeled 2-chlorophenol and 4-chlorophenol with the GROMOS 53a6 force field to study their interaction with alginates and alginic acid [23].

As for related substances, phenol and chlorobenzenes a larger number of simulation studies can be found.

For phenol a number of force fields have been proposed in the last two decades. Mooney et al. [24] developed an atomistic force field specially parameterized for phenol, with which liquid density and vaporization enthalpy values were obtained in close agreement with experimental data. Ferrando et al. [25] were able to reproduce vapor pressures, liquid densities and vaporization enthalpies of phenol using an anisotropic united atom force field developed for alcohols and polyalcohols. Kukzera et al. [26] calculated rotational diffusion coefficients of phenol in water using CHARMM and Zheng et al. [27] used the Gromos 96-43a2 united atom force field to study the interfacial behavior of phenol in dodecane/water [27].

Using the OPLS-AA force field, diffusion coefficients of phenol in water (bulk and confined environment) were obtained by Lock et al. [28] and in a polyamide membrane by Hughes et al. [29]. Plugatyr et al. [30] studied the hydration structure and dynamics of phenol in saturated water describing phenol with the rigid model of Mooney et al. [24]. In this work it was suggested that in addition to usual $\mathrm{H}$ bonds with the hydroxyl group of phenol, water forms $\pi$-type complexes with the center of the benzene ring.

Chlorobenzenes have been modeled with the TraPPE-EH force field producing pure saturated liquid densities and vapor pressures in good agreement with experimental results [31]. The same force field was used by Garrido et al. [32] to predict 1-hexanol/water and 1-octanol/water partition functions for the same chlorobenzenes in agreement with experimental results.

Structural studies were done for chlorobenzene, benzene and $o$-chlorotoluene modeled by AMBER, where the mutual orientation of molecules in pure state was investigated and the formation of agglomerates was reported for binary mixtures involving these molecules [33,34]. Also using the general AMBER force field, chlorobenzene was used as a probe to map the ligand binding sites on protein surfaces by molecular dynamics simulations [35].

In this work, intra-diffusion coefficients of seven chlorophenols in water have been obtained by computer simulation (molecular dynamics, MD) for dilute solutions at three different temperatures. The compounds studied were three monochlorophenols covering all the possible positions of the chlorine atom around the aromatic ring (2-chlorophenol, 3-chlorophenol, 4-chlorophenol); two di-substituted chlorophenols (2,4-dichlorophenol and 2,6-dichlorophenol); one tri-substituted chlorophenol (2,4,6-trichlorophenol) and pentachlorophenol. Given the typical size of a simulated system and the low solubility of these substances in water, only a few solute molecules can be included in a given simulation box - hence, increasing the uncertainty due to poor statistics. For this reason, the compositions studied, for each solute and temperature, correspond to molar fractions just under the experimental solubility limit. In the case of the most insoluble chlorophenols and/or at the lowest temperatures, a single solute molecule per simulation box was used in the calculations; this situation effectively obeys the infinite dilution definition (since no solute-solute interactions will occur), even if the nominal concentration of the system is above the solubility value.

Additionally, mutual diffusion coefficients were estimated for all solutes and in the case of 2-chlorophenol, compared with the available experimental results. As will be seen, the agreement between experimental and simulated values is remarkable, for all the temperatures studied. This agreement allows a good level of confidence in the values obtained by MD for the other studied chlorophenols, for which no experimental data could be found.

With the exception of 2-chlorophenol, this work reports the first determinations of diffusion coefficients of chlorophenols in water and is the first systematic study of the diffusion behavior of these systems.

\section{Simulation details}

Intra-diffusion coefficients of seven chlorophenols in dilute aqueous solutions were obtained by computer simulation (MD) as a function of temperature.

\subsection{Models}

The optimized potentials for liquid simulations all-atom (OPLS-AA) force-field [36] framework was used to model chlorophenols. This force-field models each atom as an interaction site and the potential energy is written as the sum of contributions due to bond stretching, bond angle bending, dihedral angle torsion, improper dihedral angles and non-bonded interactions (van der Waals plus electrostatic interactions). Water was modeled by TIP4P/2005 force field developed by Abascal and Vega [37], which is a four-center rigid model based on TIP4P from Jorgensen et al. [38]. Details about the exact expressions and parameters used for potential terms can be found in the original references. The charge distribution of all chlorophenols were evaluated by a least-squares fit to the electrostatic potential according to the Kollman and Singh scheme [39], from electronic densities obtained by the Hartree-Fock method and the 6-31G basis set. All quantum calculations were performed with the GAMESS-US package [40]. The molecular structures of the seven solutes and the point charges of each atom for all of them are shown in Fig. SI-1 of Supporting information.

Following the OPLS-AA parameterization, geometrical combining rules were used to compute the non-bonded Lennard-Jones interactions between sites of different types:

$\varepsilon_{i j}=\sqrt{\varepsilon_{i i} \varepsilon_{j j}}$

$\sigma_{i j}=\sqrt{\sigma_{i i} \sigma_{j j}}$

For non-bonded interactions between sites in the same molecule, only sites separated by three or more bonds are considered. Non-bonded interactions between sites separated by three bonds are scaled by a factor of 0.5 . In this work, all bonds involving hydrogen were treated as rigid, with the respective length fixed at the equilibrium distance, and the LINCS algorithm [41] was used to constrain them.

\subsection{Methods}

Molecular dynamics simulations were performed using the GROMACS package $[42,43]$, in cubic boxes containing up to 10,000 total molecules, with periodic boundary conditions in all 
three directions. The initial liquid box sizes were established according to the experimental densities. For each binary system, the following simulation protocol was applied: an initial $N p T$ equilibration run of $4 \mathrm{~ns}$ followed by a $10 \mathrm{~ns}$ long $N p T$ production run, which was used to determine the equilibrium density of the system; the box volume was then adjusted to this average density value and a $4 \mathrm{~ns} N V T$ equilibration run followed by a $10 \mathrm{~ns} N V T$ production run were performed, with the trajectory of the production run recorded every 500 time steps for subsequent analysis, which includes the calculation of the solute diffusion coefficient. The equations of motion were solved using the leapfrog integration algorithm, with a time step of $1 \mathrm{fs}$. The Nosé-Hoover thermostat [44] and the Parrinello-Rahman barostat [45] were used to control the temperature and pressure (the latter only in the $N p T$ ensemble), with coupling constants of 0.1 and $2.0 \mathrm{ps}$, respectively. An initial velocity obtained from a Maxwell distribution at the desired initial temperature has been assigned to all atoms.

In all simulations a neighbor list, with a radius of $10 \AA$, was used and was updated every 5 time steps. Both non-bonded Lennard-Jones and electrostatic potential were truncated by using cut-offs of $12 \AA$ and $10 \AA$, respectively and analytical tail corrections to dispersion terms were added. The long-range electrostatic (Coulombic) interactions beyond the cutoff were calculated using the particle-mesh Ewald method. Before the molecular dynamics runs, the boxes were subjected to energy minimization by the steepest descent method to a maximum force of $10 \mathrm{~kJ} / \mathrm{mol} \mathrm{nm}$, with a maximum number of steps of $1 \times 10^{6}$.

For each state point and system, a total of 20 independent simulation sequences were performed, each one starting from a different initial configuration. The diffusion coefficients were calculated for each trajectory and the average values and the respective standard errors are reported below.

\subsection{Calculations}

The intra-diffusion coefficients of different solutes in water $(D)$ were calculated from the linear part of the mean square displacement of the center of mass of the solute molecules according to the Einstein equation:

$D_{1}=\frac{1}{6 N} t \rightarrow \infty \frac{\mathrm{d}}{\mathrm{d} t} \sum_{i=1}^{N}\left\langle\left[\vec{r}_{i}(t)-\vec{r}_{i}(0)\right]^{2}\right\rangle$

where $\left[\vec{r}_{i}(t)-\vec{r}_{i}(0)\right]^{2}$ is the mean square displacement of solute and the \langle\rangle brackets stand for average over time. The summation extends to all solute molecules in the simulation box $(N)$. The same calculation was also done for water and estimations of mutual diffusion coefficients for chlorophenol/water systems were obtained using the Darken equation [46], considering dilute solutions:
$D_{12}=Q\left(x_{1} D_{2}+x_{2} D_{1}\right)$

where $D_{12}$ is the mutual diffusion coefficient, $x_{1}$ and $D_{1}$ are, respectively the mole fraction and the intra-diffusion coefficient of chlorophenols and $x_{2}$ and $D_{2}$ are the same properties for water. $Q$ is the thermodynamic factor, given by

$Q=1+\left(\frac{\partial \ln \gamma_{1}}{\partial \ln x_{1}}\right)_{T, P}$

which, for these generally dilute solutions, is assumed to be close to unity. In all the cases, the obtained mutual diffusion coefficients are almost identical to intra-diffusion coefficients of the solutes, given its low concentration for the systems studied.

\subsection{Systems}

Seven different binary systems have been studied in the present work: 2-chlorophenol, 3-chlorophenol, 4-chlorophenol, 2,4-dichlorophenol, 2,6-dichlorophenol, 2,4,6-trichlorophenol and pentachlorophenol in water and at three different temperatures $(277.15,298.15$ and $323.15 \mathrm{~K})$. For each system, the amount of solute and water molecules in the simulation boxes was chosen in order to obtain compositions slightly below the solubility limit for each system and temperature [47-50]. In some cases (e.g., 2,4,6-trichlorophenol and pentachlorophenol) that choice was not feasible given the low solubility of the solutes in water. In these cases, we have chosen to build the simulated system with just one solute molecule surrounded by 999 water molecules, which effectively correspond to an infinite solution condition. The 2-chlorophenol/water system was studied at two different compositions in order to better compare our simulation results with the experimental measurements of Niesner and Heintz [19], which as far as we know are the only experimental results available in the literature. The state points at which the seven chlorophenol/water systems were studied in the present work are summarized in Table 1.

In the case of 2-chlorophenol/water system, simulations using two different box sizes ( 3000 and 5000 total molecules) were done for the same composition at each temperature (Table 1). The differences in the average diffusion coefficients between the two sets of simulation results for each temperature were found to be within the simulation uncertainties and the average value between the two sets was taken as the final result.

The molecular models used were tested simulating pure water and 2-chlorophenol (the only chlorophenol that is liquid at room temperature) by MD. For pure water, simulation boxes with 1600 molecules were prepared and a simulation protocol similar to that of the mixtures was applied at the same temperatures (277.15, 298.15 and $323.15 \mathrm{~K}$ ). In the case of pure 2-chlorophenol, simulation boxes were built with 400 molecules and a slightly

Table 1

Compositions studied in the simulations for each system and temperature as well as the corresponding proportion solute/solution molecules.

\begin{tabular}{|c|c|c|c|c|c|c|}
\hline \multirow[b]{2}{*}{ Solute } & \multicolumn{2}{|l|}{$T=277.15 \mathrm{~K}$} & \multicolumn{2}{|l|}{$T=298.15 \mathrm{~K}$} & \multicolumn{2}{|l|}{$T=323.15 \mathrm{~K}$} \\
\hline & $x_{1}$ & Proportion & $x_{1}$ & Proportion & $x_{1}$ & Proportion \\
\hline \multirow[t]{3}{*}{ 2-Chlorophenol } & 0.001 & $10 / 10000$ & 0.001 & $10 / 10000$ & 0.001 & $10 / 10000$ \\
\hline & 0.002 & $6 / 3000$ & 0.003 & $9 / 3000$ & 0.003 & $9 / 3000$ \\
\hline & & $10 / 5000$ & & $15 / 5000$ & & $15 / 5000$ \\
\hline 3-Chlorophenol & 0.002 & $6 / 3000$ & 0.003 & $9 / 3000$ & 0.003 & $9 / 3000$ \\
\hline 4-Chlorophenol & 0.00233 & $7 / 3000$ & 0.003 & $9 / 3000$ & 0.003 & $9 / 3000$ \\
\hline 2,4-Dichlorophenol & Infinite dilution & $1 / 1000$ & $5 \times 10^{-4}$ & $3 / 6000$ & $6.67 \times 10^{-4}$ & $4 / 6000$ \\
\hline 2,6-Dichlorophenol & Infinite dilution & $1 / 1000$ & Infinite dilution & $1 / 1000$ & $3.33 \times 10^{-4}$ & $2 / 6000$ \\
\hline 2,4,6-Trichlorophenol & Infinite dilution & $1 / 1000$ & Infinite dilution & $1 / 1000$ & Infinite dilution & $1 / 1000$ \\
\hline Pentachorophenol & Infinite dilution & $1 / 1000$ & Infinite dilution & $1 / 1000$ & Infinite dilution & $1 / 1000$ \\
\hline
\end{tabular}


Table 2

Densities and self-diffusion coefficients of pure compounds obtained by computer simulation in comparison with experimental data and their respective percent deviation.

\begin{tabular}{|c|c|c|c|c|c|c|}
\hline \multirow{2}{*}{$\begin{array}{l}\text { Water } \\
T / \mathrm{K}\end{array}$} & \multicolumn{3}{|l|}{$\rho\left(\mathrm{kg} / \mathrm{m}^{3}\right)$} & \multicolumn{3}{|l|}{$D \times 10^{9}\left(\mathrm{~m}^{2} / \mathrm{s}\right)$} \\
\hline & Simulation & Experiment & $\begin{array}{l}\text { Dev. } \\
(\%)\end{array}$ & Simulation & Experiment & $\begin{array}{l}\text { Dev. } \\
(\%)\end{array}$ \\
\hline 277.15 & $1000.5 \pm 0.1$ & 999.97 [51] & 0.06 & $1.199 \pm 0.007$ & $\begin{array}{l}1.19[52] \\
1.26[53]\end{array}$ & $\begin{array}{l}0.7 \\
-4.9\end{array}$ \\
\hline 298.15 & $997.3 \pm 0.1$ & 997.05 [51] & 0.03 & $2.13 \pm 0.02$ & $\begin{array}{l}2.23[52] \\
2.30[53]\end{array}$ & $\begin{array}{l}-4.6 \\
-7.5\end{array}$ \\
\hline 323.15 & $987.8 \pm 0.1$ & $988.03[51]$ & -0.03 & $3.57 \pm 0.02$ & $3.86[53]$ & -7.5 \\
\hline
\end{tabular}

2-Chlorophenol

\begin{tabular}{llll} 
& $\rho\left(\mathrm{kg} / \mathrm{m}^{3}\right)$ & & \\
\cline { 2 - 4 }$T / \mathrm{K}$ & Simulation & Experiment & Deviation $(\%)$ \\
\hline 298.15 & $1296.1 \pm 0.2$ & $1258.9[54]$ & 3.0 \\
313.15 & $1279.1 \pm 0.2$ & $1241.4[55]$ & 3.0 \\
\hline
\end{tabular}

different simulation protocol was followed: a pre-equilibration stage consisting of a first $N p T$ run of 500 ps at 1 bar followed by five $N p T$ simulations with the same length and the pressure successively set to $500,300,100,50$ and 20 bar; after this stage, the system was equilibrated for $8 \mathrm{~ns}$ at 1 bar and finally a $N p T$ production run of $20 \mathrm{~ns}$ was stored for further analysis. These simulations were done at 298.15 and $313.15 \mathrm{~K}$. For pure water and 2-cholorophenol, respectively, 16 and 10 independent simulation sequences were done, from different starting configurations, and the values presented below are the calculated averages. All other simulation details were the same as described for the mixtures.

The liquid densities for both pure compounds and the selfdiffusion coefficients of water obtained from the simulations are reported and compared with experimental data from the literature in Table 2. In the case of water, the agreement with the experimental densities is remarkable (better than $0.06 \%$ ) at all temperatures, and the diffusion coefficients are also well described, with a maximum deviation less than $8 \%$. It should also be noted that the self-diffusion coefficient of water at $298.15 \mathrm{~K}$ $\left[(2.13 \pm 0.02) \times 10^{-9} \mathrm{~m}^{2} / \mathrm{s}\right]$ lies between the experimental value and that of Abascal and Vega [37] $\left(2.08 \times 10^{-9} \mathrm{~m}^{2} / \mathrm{s}\right)$, who proposed the TIP4P-2005 model used here. In the case of 2-chlorophenol the agreement between simulated and experimental densities is fair, with deviations around $3 \%$.

\section{Results and discussion}

\subsection{Diffusion coefficients}

The intra-diffusion coefficients of chlorophenols (1) in dilute water (2) solutions are presented in Table 3, along with their error estimations. Given the low solute concentration of the solutions studied, the estimated mutual diffusion coefficients obtained by Eq. (4) are numerically equal to the corresponding solute intra-diffusion coefficients within their standard errors, and for simplicity they are not included in the Table 3.

As far as we know, the only study that can be found in the literature reporting diffusion coefficients for solutions of chlorophenols in water is that of Niesner and Heintz [19], who measured mutual diffusion coefficients of 2-chlorophenol/water mixtures at three temperatures $(277.2 \mathrm{~K}, 298.2 \mathrm{~K}$ and $323.2 \mathrm{~K})$ and infinite dilution using the Taylor dispersion method. In Fig. 1, the results of the present work are compared with those from Niesner and Heintz. First of all, it is important to note that the simulated mutual diffusion coefficients increase as the mole fraction decreases for all the three temperatures studied, as it is generally observed for
Table 3

Intra-diffusion coefficients of chlorophenols (1) and water (2) for binary systems chlorophenols/water obtained by simulation at different temperatures.

\begin{tabular}{|c|c|c|c|}
\hline & $\begin{array}{l}T=277.15 \mathrm{~K} \\
x_{1} \\
\end{array}$ & $10^{9} D_{1}\left(\mathrm{~m}^{2} / \mathrm{s}\right)$ & $10^{9} D_{2}\left(\mathrm{~m}^{2} / \mathrm{s}\right)$ \\
\hline \multirow[t]{2}{*}{ 2-Chlorophenol } & 0.001 & $0.49 \pm 0.01$ & $1.231 \pm 0.005$ \\
\hline & 0.002 & $0.46 \pm 0.02$ & $1.186 \pm 0.007$ \\
\hline 3-Chlorophenol & 0.002 & $0.47 \pm 0.01$ & $1.192 \pm 0.008$ \\
\hline 4-Chlorophenol & 0.00233 & $0.45 \pm 0.01$ & $1.187 \pm 0.005$ \\
\hline 2,4-Dichlorophenol & Infinite dilution & $0.40 \pm 0.02$ & $1.17 \pm 0.01$ \\
\hline 2,6-Dichlorophenol & Infinite dilution & $0.37 \pm 0.03$ & $1.16 \pm 0.01$ \\
\hline 2,4,6-Trichlorophenol & Infinite dilution & $0.34 \pm 0.02$ & $1.15 \pm 0.01$ \\
\hline \multirow[t]{3}{*}{ Pentachlorophenol } & Infinite dilution & $0.27 \pm 0.03$ & $1.145 \pm 0.007$ \\
\hline & \multicolumn{3}{|l|}{$T=298.15 \mathrm{~K}$} \\
\hline & $x_{1}$ & $10^{9} D_{1}\left(\mathrm{~m}^{2} / \mathrm{s}\right)$ & $10^{9} D_{2}\left(\mathrm{~m}^{2} / \mathrm{s}\right)$ \\
\hline \multirow[t]{2}{*}{ 2-Chlorophenol } & 0.001 & $0.91 \pm 0.02$ & $2.198 \pm 0.005$ \\
\hline & 0.003 & $0.86 \pm 0.02$ & $2.11 \pm 0.01$ \\
\hline 3-Chlorophenol & 0.003 & $0.83 \pm 0.02$ & $2.10 \pm 0.01$ \\
\hline 4-Chlorophenol & 0.003 & $0.82 \pm 0.03$ & $2.11 \pm 0.01$ \\
\hline 2,4-Dichlorophenol & 0.0005 & $0.78 \pm 0.04$ & $2.190 \pm 0.007$ \\
\hline 2,6-Dichlorophenol & Infinite dilution & $0.73 \pm 0.03$ & $2.08 \pm 0.01$ \\
\hline 2,4,6-Dichlorophenol & Infinite dilution & $0.58 \pm 0.03$ & $2.07 \pm 0.01$ \\
\hline \multirow[t]{3}{*}{ Pentachlorophenol } & Infinite dilution & $0.53 \pm 0.04$ & $2.061 \pm 0.009$ \\
\hline & \multicolumn{3}{|l|}{$T=323.15 \mathrm{~K}$} \\
\hline & $x_{1}$ & $10^{9} D_{1}\left(\mathrm{~m}^{2} / \mathrm{s}\right)$ & $10^{9} D_{2}\left(\mathrm{~m}^{2} / \mathrm{s}\right)$ \\
\hline \multirow[t]{2}{*}{ 2-Chlorophenol } & 0.001 & $1.63 \pm 0.03$ & $3.692 \pm 0.008$ \\
\hline & 0.003 & $1.49 \pm 0.04$ & $3.57 \pm 0.02$ \\
\hline 3-Chlorophenol & 0.003 & $1.41 \pm 0.03$ & $3.54 \pm 0.02$ \\
\hline 4-Chlorophenol & 0.003 & $1.45 \pm 0.03$ & $3.55 \pm 0.01$ \\
\hline 2,4-Dichlorophenol & 0.000667 & $1.37 \pm 0.05$ & $3.66 \pm 0.02$ \\
\hline 2,6-Dichlorophenol & 0.000333 & $1.43 \pm 0.06$ & $3.68 \pm 0.01$ \\
\hline 2,4,6-Trichlorophenol & Infinite dilution & $1.1 \pm 0.1$ & $3.46 \pm 0.02$ \\
\hline Pentachlorophenol & Infinite dilution & $0.97 \pm 0.08$ & $3.46 \pm 0.02$ \\
\hline
\end{tabular}

organic solutes in water. Most of the structural characteristics of dilute aqueous solutions are mainly determined by the unique properties of water, in particular its tridimensional network (even in the liquid state) due to hydrogen bonding. As the solute concentration decreases, its mobility increases as it becomes less hindered to move around water cavities and so the diffusion coefficient increases. Fig. 1 shows that the agreement between simulated and experimental results is very good, especially considering the trend that diffusion coefficients exhibit with decreasing solute mole fraction and comparing very well at infinite dilution limit.

These results suggest that both the model and the method used are suitable to describe the diffusion of 2-chlorophenol in water

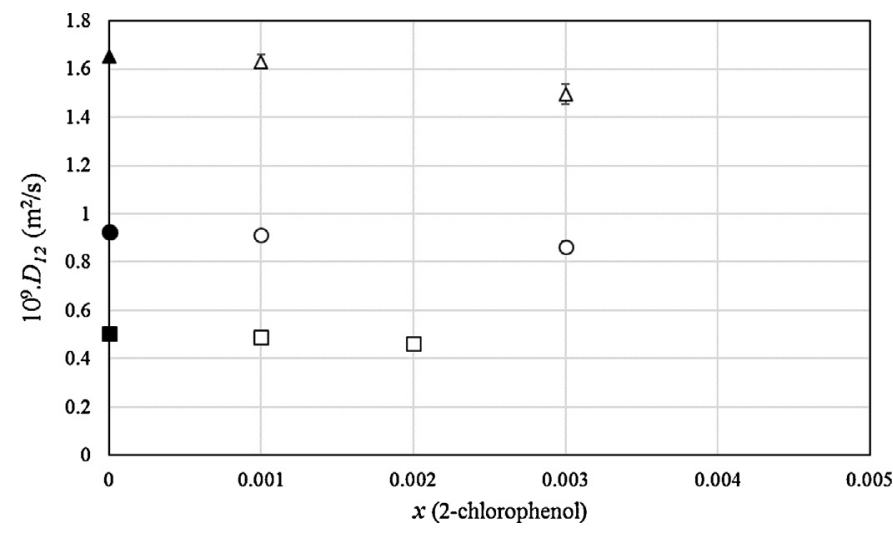

Fig. 1. Mutual diffusion coefficients of 2-chlorophenol in water as a function of composition at three temperatures (squares, $277.15 \mathrm{~K}$; circles, $298.15 \mathrm{~K}$; triangles, $323.15 \mathrm{~K}$ ). Filled symbols: experimental results (Ref. [19]); empty symbols: simulation results. 


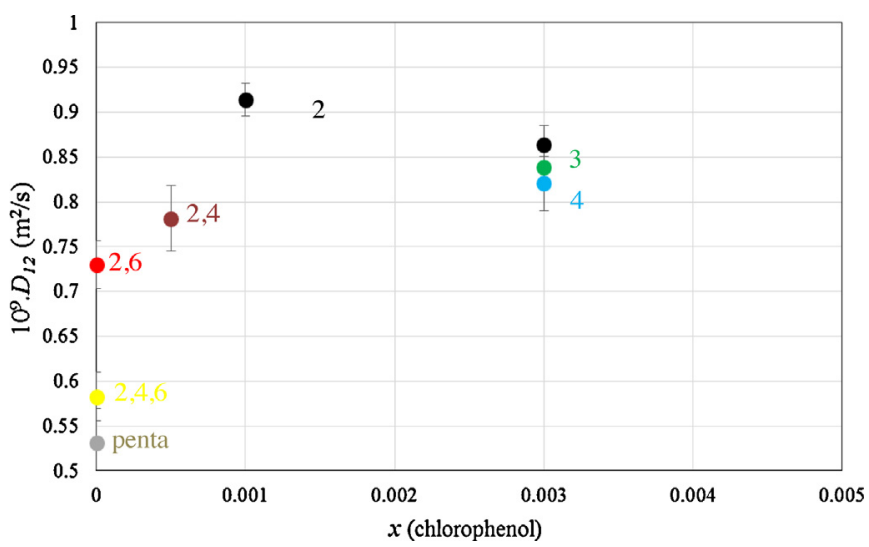

Fig. 2. Mutual diffusion of chlorophenols in water obtained by simulation at 298.15 K. ๑, 2-chlorophenol (2); , 3-chlorophenol (3); , 4-chlorophenol (4); 2,4-dichlorophenol $(2,4)$; 2,6-dichlorophenol $(2,6)$; 2,4,6-trichlorophenol (2,4,6); pentachlorophenol (penta).

providing a good degree of confidence in the prediction of the diffusion coefficients of the other chlorophenols in aqueous solutions.

The mutual diffusion coefficients for all the solutes at $298.15 \mathrm{~K}$ are shown in Fig. 2, for comparison. It can be seen that diffusivities are primarily dependent on the molecular weight of the solute: diffusion coefficients decrease as the number of chlorine atoms in the solute molecule increases and that is apparent in Fig. 3 where intra-diffusion coefficients are plotted as a function of the inverse of square root of solute molecular weight. This relation, predicted by the Chapman-Enskog theory is fairly linear at $277.15 \mathrm{~K}$, with more pronounced deviations as the temperature increases. The experimental results of mutual diffusion coefficients for phenol from Niesner and Heintz are also included in the figure. It is important to note that in Fig. 3 diffusion coefficients at different compositions are compared, in particular at 298.15 and $323.15 \mathrm{~K}$, which in part can explain the observed deviations.

The obtained diffusion coefficients for solutes with the same molecular weight present values which do not differ much from each other. Nevertheless, simulations are able to distinguish between different isomers, being sensitive to the position of chlorine atoms around the aromatic ring. In the case of the monochlorophenols, 2-chlorophenol presents slightly higher diffusion coefficients than 3-chlorophenol and 4-chlorophenol despite the molecular

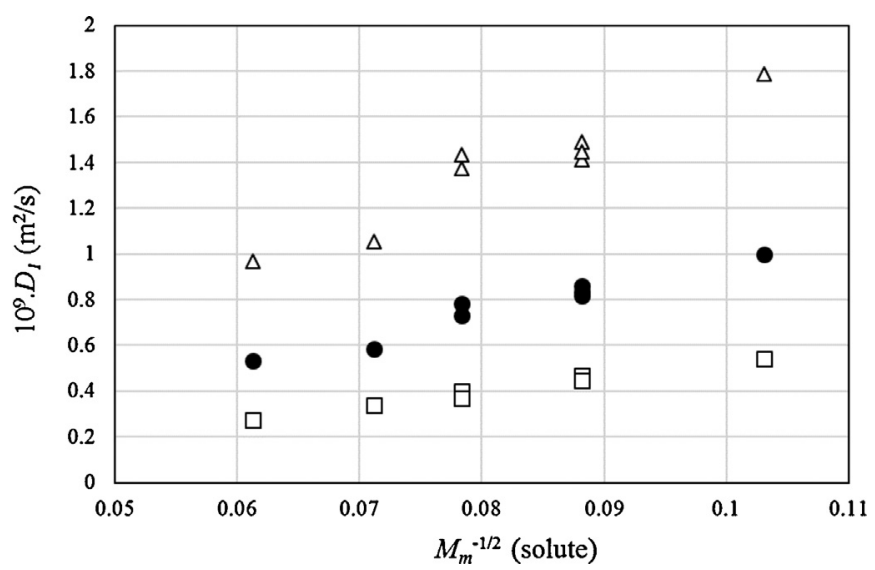

Fig. 3. Intra-diffusion coefficients of chlorophenols and phenol (mutual diffusion coefficient from Ref. [19]) as a function of solute molecular weight at $277.15 \mathrm{~K}$ (squares), $298.15 \mathrm{~K}$ (circles) and $323.15 \mathrm{~K}$ (triangles). similitude between them. The diffusion coefficients of the two dichlorophenols are relatively close to each other: those 2,4-dichlorophenol are higher at the lowest temperatures but the inverse occurs at the highest temperature. As will be shown, the specific interactions between each chlorophenol and water can be used to rationalize the dynamic behavior of these solutions.

\subsection{Structure}

In order to gain a deeper knowledge on the interactions and the structure of the solutions studied, radial distribution functions $[g(r)]$ of water sites around selected solute sites were obtained from the $N V T$ production trajectories for all solutes. The radial distribution functions of $\mathrm{H}$ or $\mathrm{O}$ from water around $\mathrm{Cl}, \mathrm{O}$ and $\mathrm{H}$ (hydroxyl) from solutes at $25^{\circ} \mathrm{C}$ are shown and compared for monochlorophenols in Fig. 4, dichlorophenols in Fig. 5 and the solutes with more than two chlorine atoms in Fig. 6. Spatial distribution functions of water molecules (centers of mass) around the solutes have also been calculated in order to obtain a three dimensional view of the population of water molecules around chlorophenol molecules. The isodensity surfaces at fixed values of $\rho_{\text {local }} / \rho_{\text {bulk }}$ are shown in Fig. 7 for 4 -chlorophenol and 2,4dichlorophenol.

$g(r)$ for $\mathrm{H}$ from water around chlorine are very similar for all the solutes. However, for monochlorophenols (Fig. 4) at very low distances, $g(r)$ is more intense for 3-chlorophenol and 4-chlorophenol than for 2-chlorophenol, which can be explained by a more effective steric hindrance in the latter because of the proximity of the hydroxyl group. For these three solutes, there is no indication of any specific interaction between the chlorine bonded to the aromatic ring and the hydrogen atom of water. In fact, $g(r)$ is below 1 for all the distances, which shows that the average local density of water molecules around chlorine atoms is lower than the bulk density, suggesting an overall depletion of water around chlorine. The preference of water toward the hydroxyl group can explain this result. The spatial distribution functions show, however, that despite the preferential location of water molecules around the hydroxyl group of the chlorophenol, there are also regions of space around the chlorine atoms where a significant density of water molecules can be found.

The picture is completely different when the $g(r)$ for hydroxyl/ water pairs are analyzed. For the three monochlorophenols, the first peaks for the pair $\mathrm{H}$ (chlorophenol)/O (water) are much more intense than those for $\mathrm{H}$ (water)/O (chlorophenol) (follows the charge differences between the relevant atoms), indicating that water approaches the hydroxyl group of the solutes preferably by oxygen rather than hydrogen. Additionally the peaks are much more intense for 3-chlorophenol and 4-chlorophenol than for 2-chlorophenol. The $g(r)$ confirm the existence of hydrogen bonding between water and the hydroxyl group of chlorophenols, because the first peak is narrow with its maximum at low distances $(0.18-0.19 \mathrm{~nm})$. However, the association is less effective in the case of 2-chlorophenol, probably due to the presence of the chlorine atom. This can explain the slightly higher diffusion coefficient of 2-chlorophenol relatively to the other isomers since - a less effective interaction with the solvent would increase the mobility of the solute.

From the integration of the radial and spatial distribution functions, the number of hydrogen bonds per solute molecule were obtained for all the systems at all the temperatures and are shown in Fig. 8. This determination was subject to some criteria, such as, oxygen was the only acceptor considered, the distance between donor and acceptor was lower than $0.35 \mathrm{~nm}$ and the angle between hydrogen-donor-acceptor lower than $30^{\circ}$. As can be seen in Fig. 8 , 

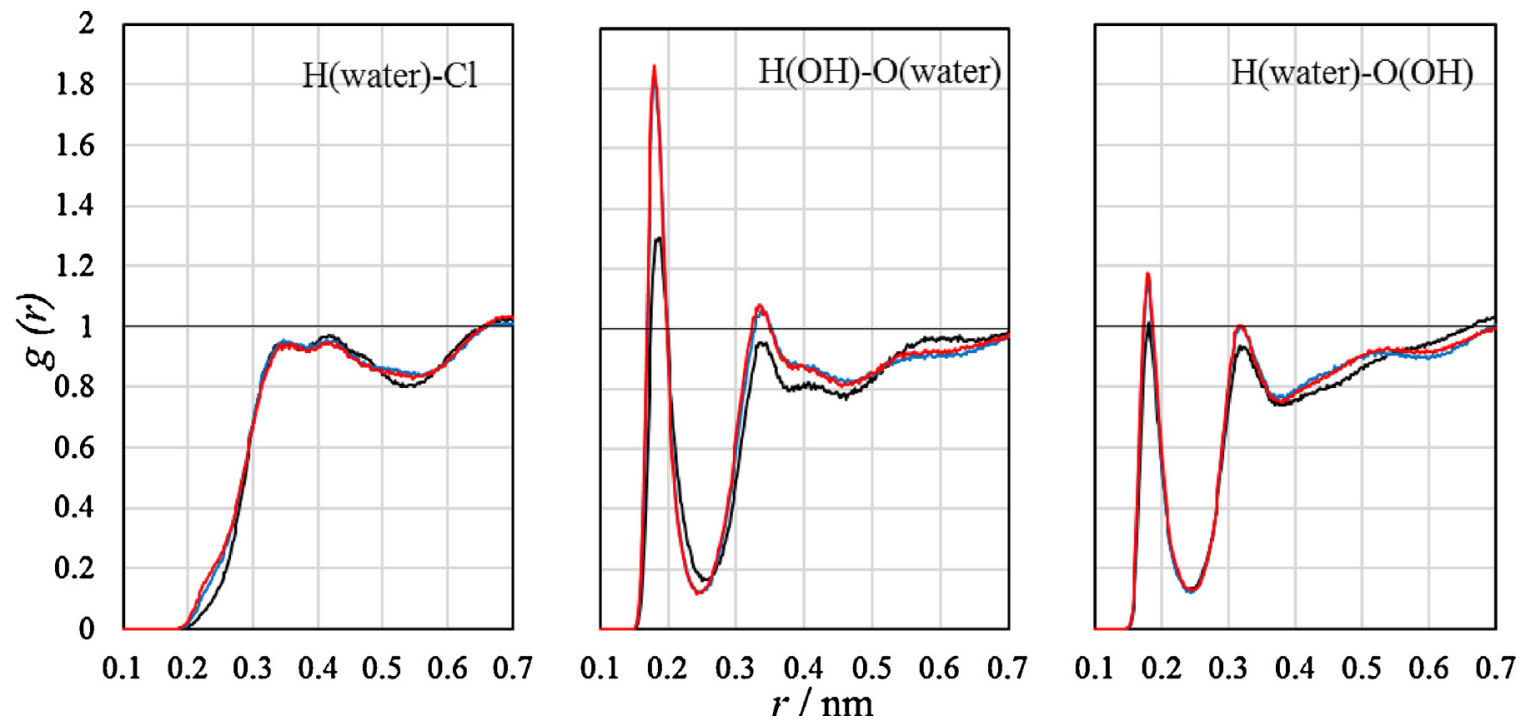

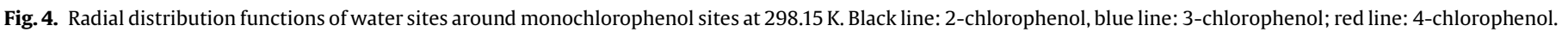

the system 2-chlorophenol/water presents much less hydrogen bonds per solute than either 3-chlorophenol or 4-chlorophenol, confirming the weaker interaction with water.

Sánchez-Flores et al. [16] have suggested the existence of an intramolecular hydrogen bond in 2-chlorophenol between the chlorine and the hydrogen from the hydroxyl group. Fig. 9a displays the intramolecular radial distribution functions corresponding to $\mathrm{Cl}-\mathrm{H}$ (hydroxyl) pair for all the monochlorophenols. In fact the peak for 2-chlorophenol is particularly intense with a maximum at a short distance (ca $0.25 \mathrm{~nm}$ ), that lies within what is usually considered as hydrogen bond. This intramolecular hydrogen bond reduces the availability of the hydroxyl group from chlorophenol to act as donor toward water molecules, therefore reducing the solute-solvent interaction. The same effect is further confirmed by the angle distribution of the dihedral $\mathrm{H}-\mathrm{O}-\mathrm{C}-\mathrm{C}(\mathrm{Cl}$ side) for the three monochlorophenols (Fig. 9c). For 2-chlorophenol, the angle distribution shows a single peak at $0^{\circ}$ (cis conformation, with $\mathrm{O}-\mathrm{H}$ pointing to $\mathrm{Cl}$ ), whereas in the case of 3-chlorophenol and 4-chlorophenol two peaks are found, at $0^{\circ}$ and $180^{\circ}$, with very similar populations.
In Fig. 5, $g(r)$ for the two dichlorophenols are compared and the observations are slightly different from those of monochlorophenols. The radial distribution functions for $\mathrm{H}$ (water)- $\mathrm{Cl}$ pairs of both solutes are almost indistinguishable, independently of the position of the chlorine being ortho or para. On the other hand, the first peaks for the pairs involving $\mathrm{H}$ and $\mathrm{O}$ present similar intensities for 2,6-dichlorophenol and 2,4-dichlorophenol. It is interesting to note that the peak from $\mathrm{H}$ (chlorophenol $\mathrm{OH}$ )-O (water) is more intense for 2,6-dichlorophenol than for 2,4-dichlorophenol whereas the inverse order is observed for the peak from $\mathrm{H}$ (water)- $\mathrm{O}$ (chlorophenol $\mathrm{OH}$ ) and this trend does not follow the order of charge difference between acceptor and hydrogen. The higher steric hindrance in 2,6-dichlorophenol (due to the presence of two chlorine atoms in ortho position) makes it more difficult for the solute oxygen to act as donor.

The overall number of hydrogen bonding interactions are very similar for both dichlorophenols, which can explain the fact that 2,4-dichlorophenol and 2,6-dichlorophenol exhibit diffusion coefficients that are very similar, as discussed in the previous section.
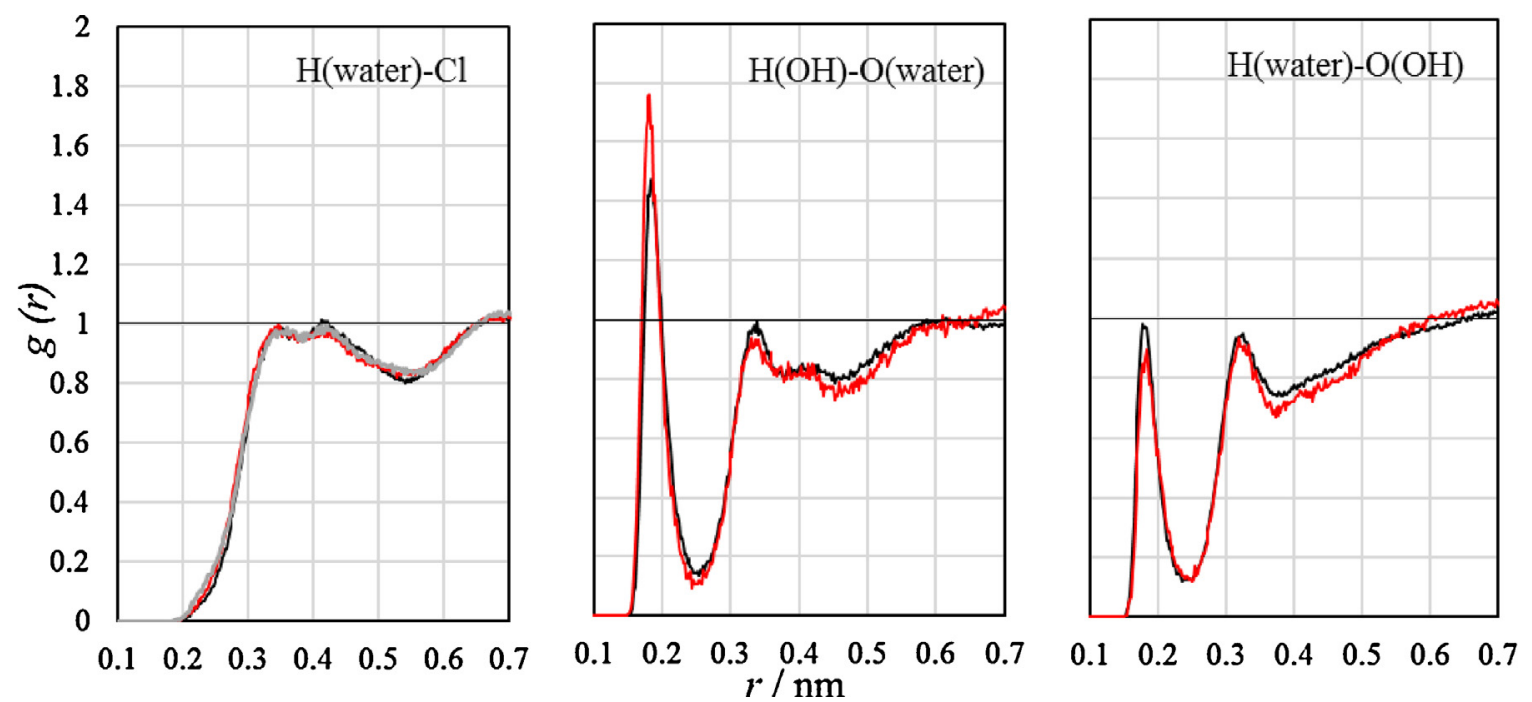

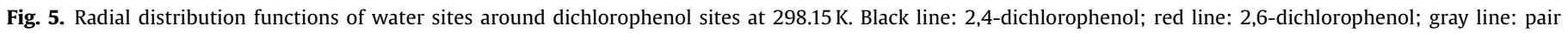
involving para-chlorine in 2,4-dichlorophenol. 

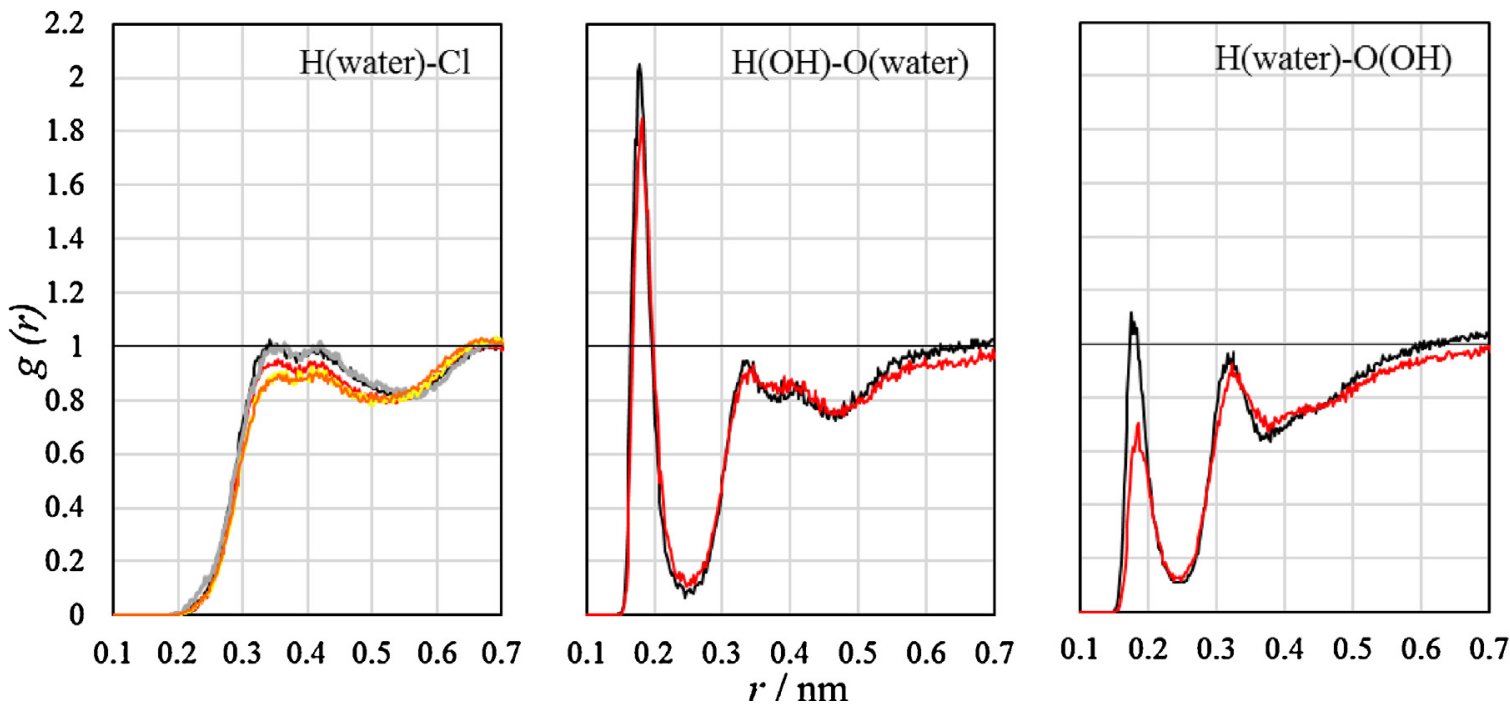

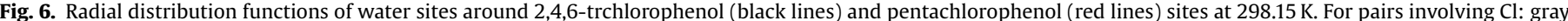
line, para-chlorine from 2,4,6-trichlorophenol; orange line, meta-chlorine from pentachlorophenol; yellow line, para-chlorine from pentachlorophenol.

As for monochlorophenols, the spatial distribution functions of 2,4-dichlorophenol and 2,6-dichlorophenol (Fig. 7) reveal that water molecules are preferably located around the hydroxyl group of the solute but also, to a lower extent, around chlorine atoms. The intramolecular interaction between the ortho chlorine and the hydroxyl hydrogen seems to be stronger in 2,4-dichlorophenol than in 2,6-dichlorophenol, as indicated by the more intense peak shown by the former in $g(r)$ (Fig. 9b). Accordingly, a clear predominance of the cis conformation is observed in the dihedral $\mathrm{H}-\mathrm{O}-\mathrm{C}-\mathrm{C}$ (ortho $\mathrm{Cl}$ side) for 2,4-dichlorophenol, with the angle distribution favoring $0^{\circ}$, whereas for 2,6-dichlorophenol similar probabilities are observed at $0^{\circ}$ and $180^{\circ}$ (Fig. 9d). Furthermore, since 2,6-dichlorophenol has two chlorine atoms in ortho positions, a higher steric hindrance is expected in comparison 1a)

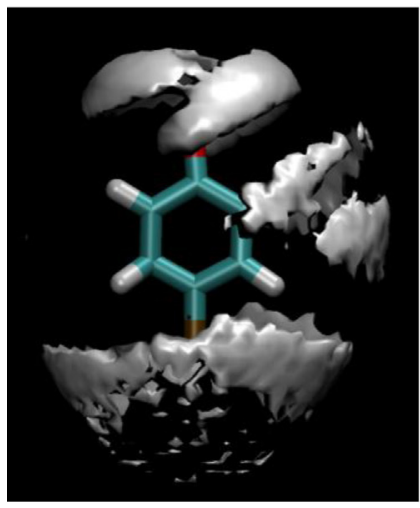

2a)

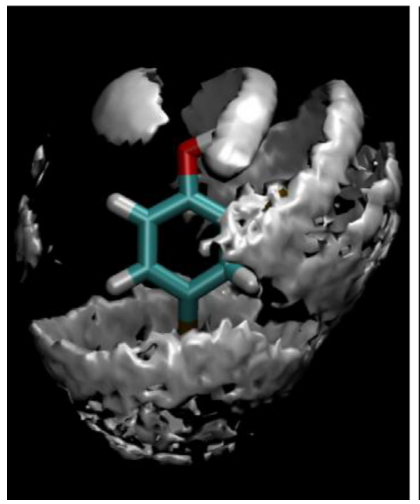

1b)

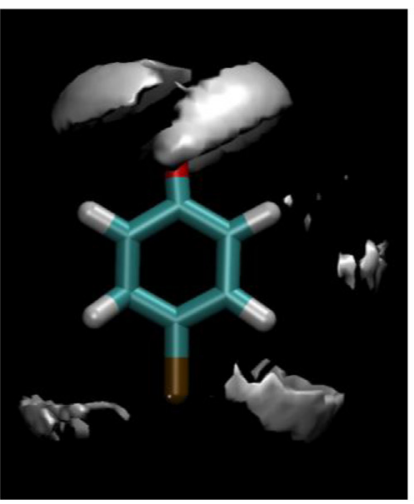

2b)

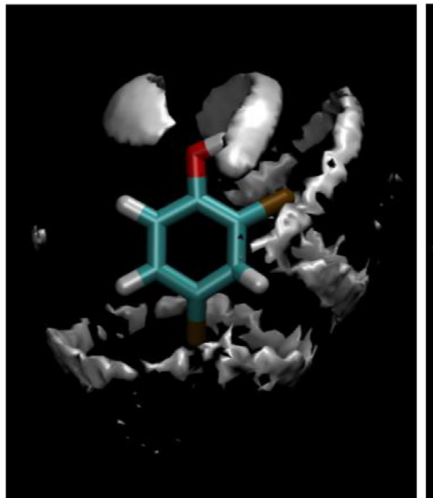

1c)

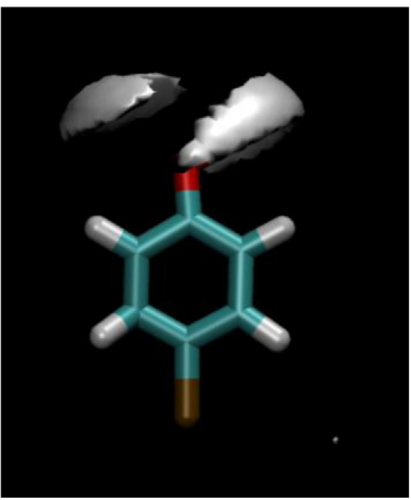

2c)

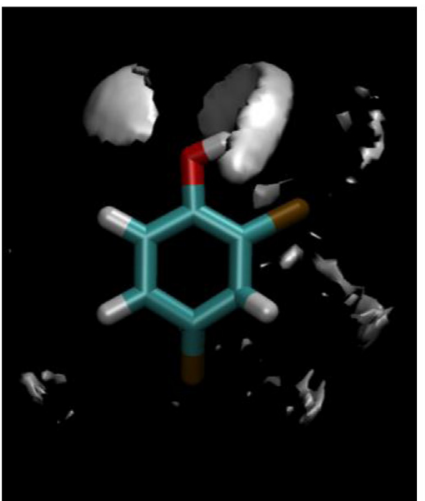

1d)

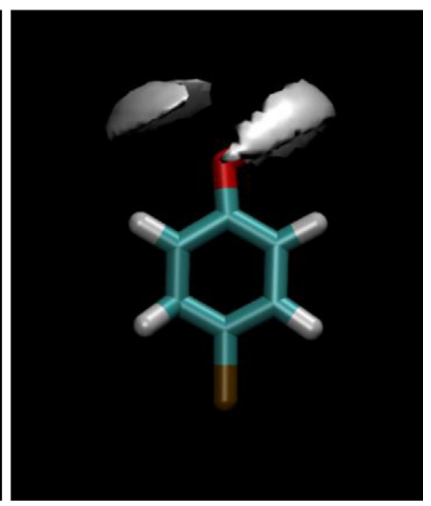

2d)

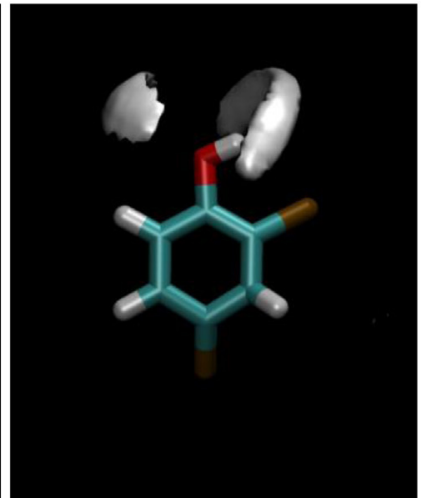

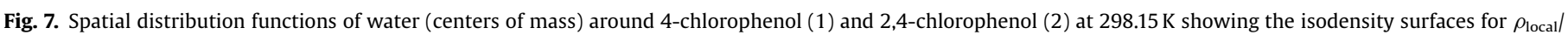
$\rho_{\text {bulk }}=2.0(\mathrm{a}), 2.25$ (b), 2.5 (c) and 3.0 (d). 


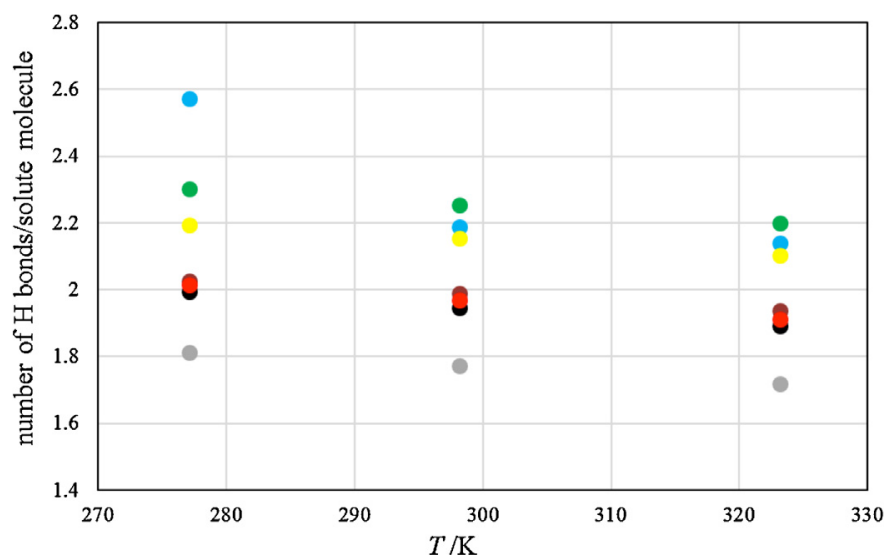

Fig. 8. Number of hydrogen bonds between water and chlorophenols per solute molecule as a function of temperature. ๑, 2-chlorophenol;, 3 -chlorophenol; $\bigcirc$, 4-chlorophenol; , 2,4-dichlorophenol; , 2,6-dichlorophenol; , 2,4,6trichlorophenol; , pentachlorophenol. with 2,4-dichlorophenol, rendering the interaction hydroxyl group/water more difficult.

$g(r)$ for 2,4,6-triclorophenol and pentachlorophenol are compared in Fig. 6. For $\mathrm{H}$ (water) $-\mathrm{Cl}$ pairs, the peaks for 2,4,6-trichlorophenol are slightly more intense than those of pentachlorophenol, which is an indication of more interactions between the solvent and chlorine atoms for the former. Additionally, for 2,4,6-trichlorophenol the number of hydrogen bonds with water is considerably higher than for pentachlorophenol, probably because the hydroxyl group in the former is more polarized in terms of charge distribution. These differences in the interaction of 2,4,6-triclorophenol and pentachlorophenol with the solvent can be an explanation for the deviations to linearity observed in plot of the diffusion coefficients against molecular weight (Fig. 3).

It is important to note that all the chlorophenols studied are weak acids whose strength increases slightly with the number of chlorine atoms, presenting $\mathrm{p} K_{\mathrm{a}}$ values that ranges from 9.37 for 4-chlorophenol to 4.74 for pentachlorophenol [50]. In experimental conditions, chlorophenols are thus partly dissociated in water, in particular those with more chlorine atoms and at lower
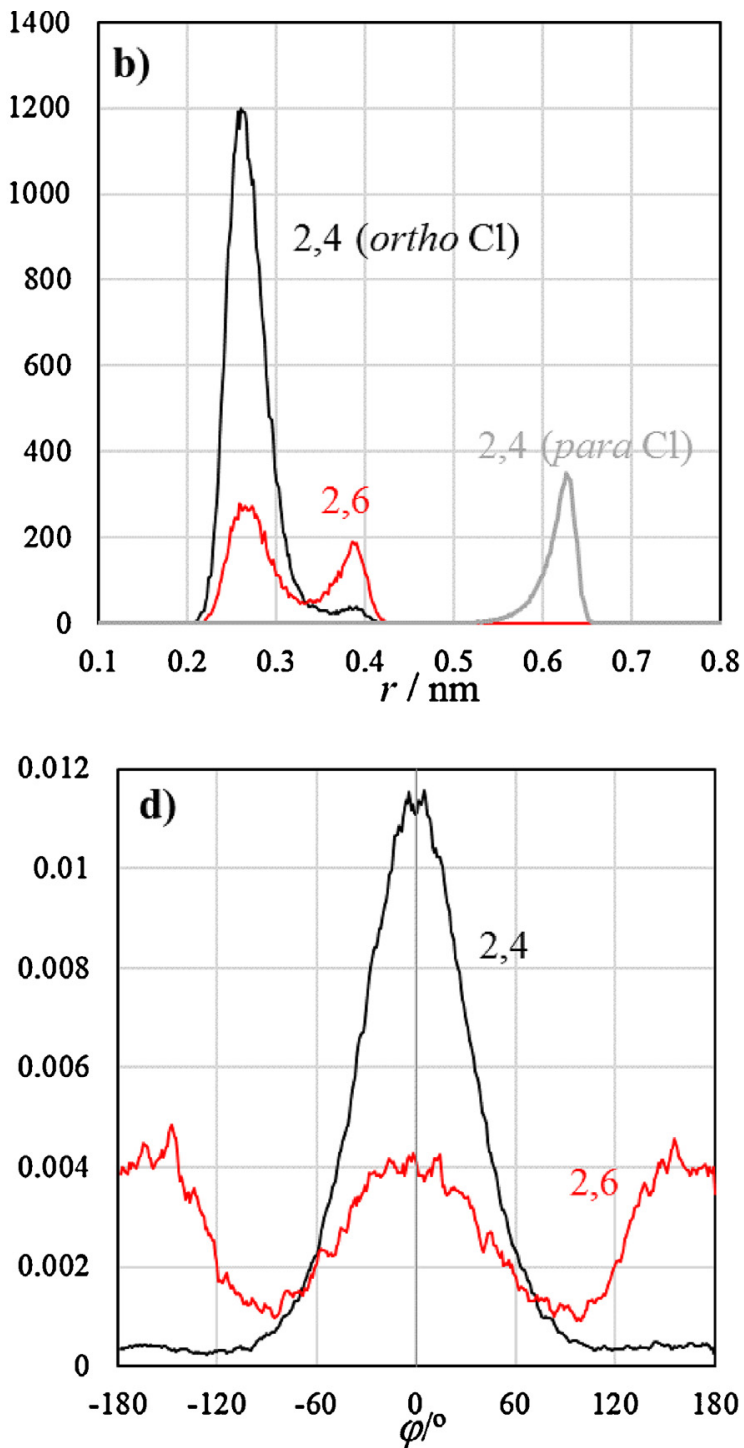

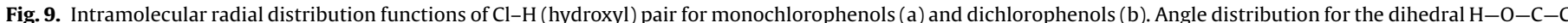

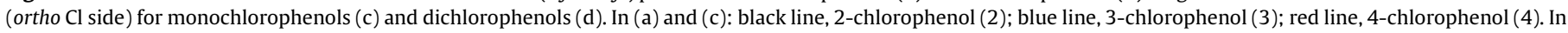
(b) and (d): black line, 2,4-dichlorophenol (2,4); red line, 2,6-dichlorophenol (2,6). In (b): gray line, $\mathrm{H}-\mathrm{Cl}$ (para) for 2,4-dichlorophenol. 
concentration. Since it is expected that the chlorophenolate ions present lower diffusion coefficients than the corresponding chlorophenols owing to the stronger electrostatic interaction with water, the values obtained by simulation can be viewed as an upper boundary for the diffusion coefficients of chlorophenols, especially for 2,4,6-trichlorophenol and pentachlorophenol.

\subsection{Correlation}

In order to evaluate the regularity of the diffusion coefficients within the chemical family of chlorophenols, the estimated mutual diffusion coefficients obtained by simulation were correlated by the Wilke-Chang equation [56], an empirical modification of the Stokes-Einstein relation, which has been widely used as a method of predicting mutual diffusion coefficients of solutes in solvents at infinite dilution (Eq. (6)).

$D_{12}=\frac{7.4 \times 10^{-8}\left(\phi . M_{m, 2}\right)^{1 / 2} T}{\eta_{2}\left(V_{m, 1}^{b}\right)^{-0.6}}$

Here $M_{m, 2}$ and $\eta_{2}$ are the molecular weight and the viscosity of the solvent, respectively, $T$ is temperature, $V_{m, 1}{ }^{b}$ is the molar volume of solute at boiling point and $\varphi$ is an association parameter. In the calculation, experimental values for the viscosity of water were used. Since the molar volumes at boiling point for chlorophenols are not available, they were estimated by Le Bas method [57], which is not able to distinguish between isomers, attributing exactly the same values for all the monochlorophenols and two dichlorophenols. For the association parameter, $\varphi$, Wilke and Chang, in their original publication, proposed the value of 2.6 whenever the solvent was water; however it has been also treated, in later works, as an adjustable parameter. Niesner and Heintz [19], for instance, found $\varphi=1.61$ as the value that best correlated their experimental results of diffusion coefficients of aromatic solutes in water. In our case, $\varphi=1.88$ provides the best fit to the simulation results. In Fig. 10, both mutual diffusion coefficients obtained by simulation and those calculated by the Wilke-Chang method for the studied chlorophenols in water are plotted as a function of $\left(V^{b}\right)^{-0.6}$ at three temperatures. The experimental diffusion coefficients for phenol in water at the studied temperatures are also included in the figure. The Wilke-Chang equation, using the optimized value of $\varphi=1.88$, correlates the results with maximum deviations of $15 \%$.

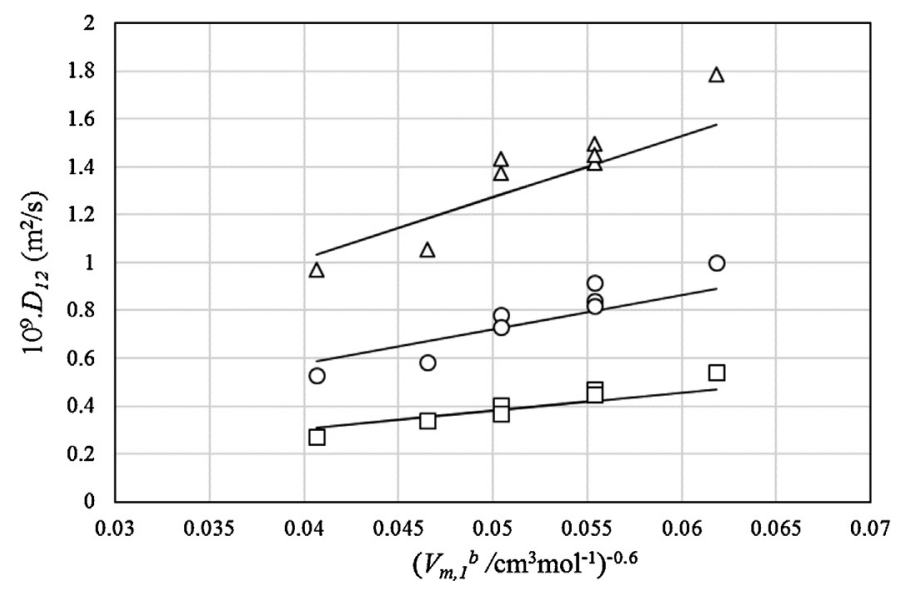

Fig. 10. Simulated mutual diffusion coefficients of chlorophenols in water as a function of molar volume of the solute at normal boiling point at $277.15 \mathrm{~K}$ (squares), $298.15 \mathrm{~K}$ (circles) and $323.15 \mathrm{~K}$ (triangles). Symbols: simulated results; solid lines: Wilke-Chang results.
The regularity is more apparent at $277.15 \mathrm{~K}$, with more pronounced deviations at higher temperatures.

\subsection{Diffusion activation energies}

From the temperature dependence of the mutual diffusion coefficients, an estimation of the average diffusion activation energies within the studied temperature range were obtained for all the systems, assuming an Arrhenius-like behavior of the diffusion of chlorophenols in water (Eq. (7)).

$D_{12}=A_{D} \exp \left(\frac{-E_{D}}{\mathrm{RT}}\right)$

Here $A_{D}$ is a pre-exponential factor and $E_{D}$ is the activation energy of diffusion. The results are presented in Table 4 . It should be noted that, for most systems, $E_{D}$ was calculated from diffusion coefficients at slightly different compositions. As can be seen, the activation energy of diffusion obtained for aqueous 2-chlorophenol $(19.4 \mathrm{~kJ} / \mathrm{mol})$ is in excellent agreement with the experimental value reported by Niesner and Heintz [19] $(19.3 \mathrm{~kJ} / \mathrm{mol})$, showing that the model used in the present work for molecular simulations is able to reproduce both the diffusion coefficients of this solute in water and their temperature dependence. As in previous studies, it was found that the activation energies of diffusion for the chlorophenols studied are all very similar, suggesting that the diffusion activation energy depends mainly on the solvent [58]. Furthermore, no particular trend or correlation with molecular structure details is detected, except the fact that the heaviest chlorophenols seem to present the highest activation energies (being 2,4,6-trichlorophenol an exception).

\section{Conclusions}

Intra-diffusion coefficients of seven chlorophenols in water were obtained by molecular dynamics simulation at three different temperatures and the corresponding mutual diffusion coefficients estimated by the Darken equation.

For 2-chlorophenol/water solutions, the mutual diffusion coefficients obtained by simulation agree with the experimental literature results, granting a high level of confidence in the results for the remaining chlorophenols. These results constitute, as far as we know, the first estimations of diffusion coefficients of chlorophenols in water by computer simulation.

The results show that the diffusion coefficients of aqueous chlorophenols are mainly sensitive to the solute molecular weight (and hence to the number of chlorine atoms in the molecule) but also to the position of chlorine atoms around the aromatic ring. In this context, the specific interactions between solutes and water also play an important role in their dynamic properties. In order to investigate such interactions and fluid structures, radial distribution functions and spatial distribution functions of water sites around some particular sites on chlorophenols were also obtained by simulation. Water molecules are preferentially located around

Table 4

Activation energy of diffusion in the temperature range of $277-323 \mathrm{~K}$ from simulation.

\begin{tabular}{llc}
\hline Solute & Composition range & $E_{D}(\mathrm{~kJ} / \mathrm{mol})$ \\
\hline 2-Chlorophenol & $0.002-0.003$ & $19.0 \pm 0.8$ \\
& 0.001 & $19.4 \pm 0.5$ \\
3-Chlorophenol & $0.002-0.003$ & $17.9 \pm 0.7$ \\
4-Chlorophenol & $0.00233-0.003$ & $19.1 \pm 0.5$ \\
2,4-Dichlorophenol & Infinite dilution -0.0006667 & $20 \pm 1$ \\
2,6-Dichlorophenol & Infinite dilution - 0.0003333 & $22.0 \pm 0.2$ \\
2,4,6-Trichlorophenol & Infinite dilution & $18.4 \pm 0.3$ \\
Pentachlorophenol & Infinite dilution & $20.4 \pm 0.7$ \\
\hline
\end{tabular}


the hydroxyl group of the solute, but also around chlorine atoms, at lower extent and longer distances.

The number of hydrogen bonds between water and chlorophenols per solute molecule was also obtained from the simulations and was used to rationalize the simulated diffusion coefficients. In general, for solutes with the same molecular weight, the higher the number of hydrogen bonds per solute molecules, the lower the diffusion coefficient of that solute in water.

The results also suggest the existence of an intramolecular hydrogen bond between the hydroxyl group and the chlorine atoms in ortho positions, reducing the availability of this group to interact with water. Steric hindrance exerted by ortho chlorine on hydroxyl group of solute molecules can also contribute to this effect. It is also seen that the most probable orientation of water toward chlorophenols directs the oxygen of water toward the hydroxyl hydrogen of the solute. This is likely due to the charge difference between the possible hydrogen bonding pairs $[\mathrm{H}(\mathrm{OH})-\mathrm{O}$ (water) . $\mathrm{H}$ (water) $-\mathrm{O}(\mathrm{OH})]$.

The diffusion coefficients obtained can be reasonably correlated by the Wilke-Chang equation, especially at the lowest temperature, provided that the association parameter is fitted to the results.

Diffusion activation energies were estimated for all the solutes in water, from the dependence of the diffusion coefficients on temperature. As for the diffusion coefficients, an excellent agreement between simulated and experimental literature results of diffusion activation energies was found for the 2-chlorophenol/ water system. On the other hand, no significant differences or trends between solutes can be detected, which is an indication of the prevalence of the solvent structure in this particular property for such dilute solutions.

\section{Acknowledgements}

LFGM acknowledges technical facilities from Centro de Geofísica de Évora of University of Évora. MCBP, LFGM and JPPR also acknowledge funding from FCT through the grant PEst-OE/QUI/UI0619/2011.

\section{Appendix A. Supplementary data}

Supplementary data associated with this article can be found, in the online version, at http://dx.doi.org/10.1016/j.fluid.2015.03.026.

\section{References}

[1] Directive 2013/39/EU, OJ L 226, 24.08.2013, p 1.

[2] M. Czaplicka, Sources and transformations of chlorophenols in the natural environment, Sci. Total Environ. 322 (2004) 21-39.

[3] M.F.F. Sze, G. McKay, An adsorption diffusion model for removal of parachlorophenol by activated carbon derived from bituminous coal, Environ. Pollut. 158 (2010) 1669-1674.

[4] M.S. Bilgili, G. Varank, E. Sekman, S. Top, D. Özçimen, R. Yazici, Modeling 4-chlorophenol removal from aqueous solutions by granular activated carbon, Environ. Model. Assess. 17 (2012) 289-300.

[5] C. Garlapati, G. Madras, Solubilities of some chlorophenols in supercritical $\mathrm{CO}_{2}$ in the presence and absence of cosolvents, J. Chem. Eng. Data 55 (2010) 273-277.

[6] O. Hamdaoui, E. Naffrechoux, Adsorption kinetics of 4-chlorophenol onto granular activated carbon in the presence of high frequency ultrasound, Ultrason. Sonochem. 16 (2009) 15-22.

[7] K.F. Chasib, Extraction of phenolic pollutants (phenol and p-chlorophenol) from industrial wastewater, J. Chem. Eng. Data 58 (2013) 1549-1564.

[8] X. Ye, L.-Y. Wong, X. Zhou, A.M. Calafat, Urinary concentrations of 2,4dichlorophenol and 2,5-dichlorophenol in the U.S. population (National Health and Nutrition Examination Survey, 2003-2010): trends and predictors, Environ. Health Perspect. 122 (4) (2014) 351-355.

[9] M.R. Criado, S.P. Torre, I.R. Pereiro, R.C. Torrijos, Optimization of a microwaveassisted derivatization-extraction procedure for the determination of chlorophenols in ash samples, J. Chromatogr. A 1024 (2004) 155-163.
[10] B. Shah, R. Tailor, A. Shah, Sorptive sequestration of 2-chlorophenol by zeolitic materials derived from bagasse fly ash, J. Chem. Technol. Biotechnol. 86 (2011) 1265-1275.

[11] S. Holopainen, V. Luukkonen, M. Nousiainen, M. Sillanpää, Determination of chlorophenols in water by headspace solid phase microextraction ion mobility spectrometry (HS-SPME-IMS), Talanta 114 (2013) 176-182.

[12] E.O. Igbinosa, E.E. Odjadjare, V.N. Chigor, I.H. Igbinosa, A.O. Emoghene, F.O. Ekhaise, N.O. Igiehon, O.G. Idemudia, Toxicological profile of chlorophenols and their derivatives in the environment: the public health perspective, Sci. World J. 460215 (2013) 1-11.

[13] M. Gómez, M.D. Murcia, R. Dams, N. Christofi, E. Gómez, J.L. Gómez, Removal efficiency and toxicity reduction of 4-chlorophenol with physical, chemical and biochemical methods, Environ. Technol. 33 (2012) 1055-1064.

[14] M. Zahoor, M. Mahramanlioglu, Removal of phenolic substances from water by adsorption and adsorption-ultrafiltration, Sep. Sci. Technol. 46 (2011) 1482-1494.

[15] R.-L. Tseng, K.-T. Wu, F.-C. Wu, R.-S. Juang, Kinetic studies on the adsorption of phenol, 4-chlorophenol, and 2,4-dichlorophenol from water using activated carbons, Manage. 91 (2010) 2208-2214.

[16] N.A. Sánchez-Flores, M. Solache, M.T. Olguín, J. Legaspe, G. Pacheco-Malagón, J. M. Saniger, E. Martinez, S. Bulbulian, J.J. Fripiat, Silicalite-1, an adsorbent for 2-, 3-, and 4-chlorophenols, Water Sci. Technol. 66 (2) (2012) 247-253.

[17] C. Pacurariu, G. Mihoc, A. Popa, S.G. Muntean, R. Ianos, Adsorption of phenol and $p$-chlorophenol from aqueous solutions on poly (styrene-codivinylbenzene) functionalized materials, Chem. Eng. J. 222 (2013) 218-227.

[18] A. Karci, Degradation of chlorophenols and alkylphenol ethoxylates, two representative textile chemicals, in water by advanced oxidation processes: the state of the art on transformation products and toxicity, Chemosphere 99 (2014) 1-18.

[19] R. Niesner, A. Heintz, Diffusion coefficients of aromatics in aqueous solution, J. Chem. Eng. Data 45 (2000) 1121-1124.

[20] A. Groß, A. Heintz, Diffusion coefficients of aromatics in nonporous PEBA membranes, J. Membr. Sci. 168 (2000) 233-242.

[21] N. Touze-Foltz, M. Ahari, M. Mendes, C. Barral, M. Gardoni, L. Mazéas, Diffusion of phenolic compounds through an HDPE geomembrane, Geotech. Eng. J. SEAGS AGSSEA 43 (2012) 19-29.

[22] M. Mendes, N. Touze-Foltz, M.G. Gardoni, L. Mazéas, Diffusion of phenolic compounds through polyethylene films, Geosynth. Int. 21 (2) (2014) 137-150.

[23] W. Plazinski, A. Plazinska, Molecular dynamics study of the interactions between phenolic compounds and alginate/alginic acid chains, New J. Chem. 35 (2011) 1607-1614.

[24] D.A. Mooney, F. Muller-Plathe, K. Kremer, Simulation studies for liquid phenol: properties evaluated and tested over a range of temperatures, Chem. Phys. Lett. 294 (1998) 135-142.

[25] N. Ferrando, V. Lachet, J.-M. Teuler, A. Boutin, Transferable force field for alcohols and polyalcohols, J. Phys. Chem. B 113 (2009) 5985-5995.

[26] K. Kuczera, J. Unruh, C.K. Johnson, G.S. Jas, Reorientations of aromatic amino acids and their side chain models: anisotropy measurements and molecular dynamics simulations, J. Phys. Chem. A 114 (2010) 133-142.

[27] H.-D. Zheng, F.-D. Wu, B.-Y. Wang, Y.-X. Wu, Molecular dynamics simulation on the interfacial features of phenol extraction by TBP/dodecane in water Comput. Theor. Chem. 970 (2011) 66-72.

[28] P.A. Lock, N.T. Skipper, Computer simulation of the structure and dynamics of phenol in sodium montmorillonite hydrates, Eur. J. Soil Sci. 58 (2007) 958-966.

[29] Z.E. Hughes, J.D. Gale, Molecular dynamics simulations of the interactions of potential foulant molecules and a reverse osmosis membrane, J. Mater. Chem. 22 (2012) 175-184.

[30] A. Plugatyr, I. Nahtigal, I.M. Svishchev, Spatial hydration structures and dynamics of phenol in sub- and supercritical water, J. Chem. Phys. 124 (2006) 024507.

[31] N. Rai, J.I. Siepmann, Transferable potentials for phase equilibria. 10. Explicithydrogen description of substituted benzenes and polycyclic aromatic compounds, J. Phys. Chem. B 117 (2013) 273-288.

[32] N.M. Garrido, I.G. Economou, A.J. Queimada, M. Jorge, E.A. Macedo, Prediction of the $n$-hexane/water and 1-octanol/water partition coefficients for environmentally relevant compounds using molecular simulation, AIChE J. 58 (6) (2012) 1929-1938.

[33] T.V. Bogdan, E.V. Isaeva, Molecular dynamics simulation of the structure of liquid chlorobenzene, ortho-chlorotoluene, and their mixtures, J. Struct. Chem. 50 (4) (2009) 640-646.

[34] T.V. Bogdan, E.V. Isaeva, Molecular dynamics simulation of liquid mixtures of benzene with chlorobenzene, J. Struct. Chem. 53 (1) (2012) 93-99.

[35] Y.S. Tan, D.R. Spring, C. Abell, C. Verma, The use of chlorobenzene as a probe molecule in molecular dynamics simulations, J. Chem. Inf. Model. 54 (2014) 1821-1827.

[36] W.L. Jorgensen, D.S. Maxwell, J. Tirado-Rives, Development and testing of the OPLS All-Atom force field on conformational energetics and properties of organic liquids, J. Am. Chem. Soc. 118 (45) (1996) 11225-11236.

[37] J.L.F. Abascal, C. Vega, A general purpose model for the condensed phases of water: TIP4P/2005, J. Chem. Phys. 123 (2005) 234505-234512.

[38] W.L. Jorgensen, J. Chandrasekhar, J.D. Madura, R.W. Impey, M.L. Klein, Comparison of simple potential functions for simulating liquid water, J. Chem. Phys. 79 (1983) 926-935.

[39] U.C. Singh, P.A. Kollman, An approach to computing electrostatic charges for molecules, J. Comput. Chem. 5 (1984) 129-145. 
[40] M.W. Schmidt, K.K. Baldridge, J.A. Boatz, S.T. Elbert, M.S. Gordon, J.H. Jensen, S. Koseki, N. Matsunga, K.A. Nguyen, S.J. Su, T.L. Windus, M. Dupuis, J.A. Montgomery, General atomic and molecular electronic-structure system, J. Comput. Chem. 14 (1993) 1347-1363.

[41] B. Hess, H. Bekker, H.J.C. Berendsen, J.G.E.M. Fraaije, LINCS: A linear constraint solver for molecular simulations, J. Comp. Chem. 18 (12) (1997) 1463-1472.

[42] D. Van Der Spoel, E. Lindahl, B. Hess, G. Groenhof, A.E. Mark, H.J.C. Berendsen, GROMACS: fast, flexible and free, J. Comput. Chem. 26 (2005) 1701-1718.

[43] S. Pronk, S. Páll, R. Schulz, P. Larsson, P. Bjelkmar, R. Apostolov, M.R. Shirts, J.C. Smith, P.M. Kasson, D. van der Spoel, B. Hess, E. Lindahl, GROMACS 4.5: a highthroughput and highly parallel open source molecular simulation toolkit Bioinformatics 29 (7) (2013) 845-854.

[44] (a) S. Nosé, A molecular-dynamics method for simulations in the canonical ensemble, Mol. Phys. 52 (1984) 255-268;

(b) W.G. Hoover, Canonical dynamics - equilibrium phase-space distributions, Phys. Rev. A 31 (1985) 1695-1697.

[45] (a) M. Parrinello, A. Rahman, Polymorphic transitions in single-crystals - a new molecular-dynamics method, J. Appl. Phys. 52 (1981) 7182-7190;

(b) S. Nosé, M.L. Klein, Constant pressure molecular-dynamics for molecularsystems, Mol. Phys. 50 (1983) 1055-1076.

[46] L.S. Darken, Diffusion, mobility and their interrelation through free energy in binary metallic systems, Trans. AIME 175 (1948) 184-201.

[47] M. Jaoui, C. Achard, M. Rogalski, Solubility as a function of temperature of selected chlorophenols and nitrophenols in aqueous solutions containing electrolytes or surfactants, J. Chem. Eng. Data 47 (2002) 297-303.

[48] J.-S. Park, N.-G. Her, Y. Yoon, Sonochemical degradation of chlorinated phenolic compounds in water: effects of physicochemical properties of the compounds on degradation, Water Air Soil Pollut. 215 (2011) 585-593.
[49] P.G. Wightman, J.B. Fein, Experimental study of 2,4,6-trichlorophenol and pentachlorophenol solubilities in aqueous solutions: derivation of a speciation-based chlorophenol solubility model, Appl. Geochem. 14 (1999) 319-331.

[50] K.-C. Ma, W.-Y. Shiu, D. Mackay, Aqueous solubilities of chlorinated phenols at $25^{\circ} \mathrm{C}$, J. Chem. Eng. Data 38 (1993) 364-366.

[51] W. Wagner, A. Pruss, The IAPWS formulation 1995 for the thermodynamic properties of ordinary water substance for general and scientific use, J. Phys. Chem. Ref. Data 31 (2) (2002) 387-535.

[52] K.T. Gillen, D.C. Douglass, M.J.R. Hoch, Self-Diffusion in Liquid Water to $-31^{\circ} \mathrm{C}$, J. Chem. Phys. 57 (12) (1972) 5117-5119.

[53] K. Krynicki, C.D. Green, D.W. Sawyer, Pressure and temperature-dependence of self-diffusion in water, Faraday Discuss. Chem. Soc. 66 (1978) 199-208.

[54] R.N. Shelar, R.Y. Borse, A.B. Sawant, Thermophysical properties of binary mixtures of 0 -dichlorobenzene and 0 -chlorophenol with diethyl ether, tetrahydrofuran, cyclohexane and anisole, Indian J. Phys. 84 (1) (2010) 81-91.

[55] R.N. Shelar, V.S. Savale, R.Y. Borse, M. Hasan, A.B. Sawant, Excess volumes and deviations in viscosities of binary mixtures of 0 -chlorophenol with di-isopropyl ether, 1,4-dioxan, diphenyl ether and $t$-butylmethyl ether, Indian J. Pure Appl. Phys. 46 (2008) 552-560.

[56] C.R. Wilke, P. Chang, Correlation of diffusion coefficients in dilute solutions, AIChE J. 1 (1955) 264-270.

[57] B.E. Poling, J.M. Prausnitz, J.P. O'Connell, The Properties of Gases and Liquids, fifth ed, McGraw-Hill, 2001.

[58] L.A.M. Pereira, L.F.G. Martins, J.R. Ascenso, P. Morgado, J.P.P. Ramalho, EJ.M. Filipe, Diffusion coefficients of fluorinated surfactants in water: experimental results and prediction by computer simulation, J. Chem. Eng. Data 59 (10) (2014) 3151-3159. 